\title{
Manufacturing Accomplices: ICT Use in Securing the Safety State at Airports
}

\author{
Thomas Østerlie, Ole Martin Asak, Ole Georg Pettersen, and Håvard Tronhus
}

\author{
Department of Computer and Information Science, \\ Norwegian University of Science and Technology, \\ Trondheim, Norway
}

\begin{abstract}
Based on a study of ICT use at an airport security checkpoint, this paper explores a possible explanation to the paradox that travelers find existing airport security measures inadequate while at the same time believing air travel to be sufficiently secure. We pursue this explanation by showing that, for the security checkpoint to function properly in relation to the overall function of the airport, travelers have to be enrolled in a particular program of action. They are then locked into this program through sanctions. Travelers are forced into participating in a system many of them find ethically and morally objectionable. Yet, active participation makes it difficult for them to object to the moral and ethical issues of their actions without damning themselves. Our explanation of the security paradox is, therefore, that while travelers remain critical of airport security, they avoid damning themselves by criticizing the system in terms of its own logic. They have been made accomplices.
\end{abstract}

Keywords: Social implications of ICT, airport security, ICT-enabled risk management, safety state, grounded theory.

\section{Introduction}

Two aircraft rammed into the World Trade Center on the morning of September 11, 2001. Pictures of the exploding aircraft and the subsequent collapse of the buildings were televised time and again in the days and weeks to follow. While in continuous development since the 1970s (Elphinstone 2008), airport security never engaged the public imagination prior to 2001. The September 11 attacks changed this.

Airport security has undergone rapid and profound changes since 2001 (Salter 2008b). Expenditures have risen correspondingly. In 2007, the International Air Transportation Association (IATA) estimated that annual expenditures on airport security had increased by U.S.\$5.6 billion worldwide since 2001 (IATA 2007). A significant part of these investments were new ICT-based security technologies. Avinor, Norway's national airport operator, reports that security expenditures have increased by 150 percent during the three-year period from 2005 to 2007 (Avinor 2007).

It is, therefore, puzzling that 7 out of 10 respondents to a recent Norwegian survey believe that existing airport security measures provide inadequate security (Steria 
2007). A study by the Norwegian Institute of Transport Economics further compounds this puzzle. In this study, 78 percent of respondents state that inadequate security measures do not contribute to less-secure flights (ТØI 2007). We refer to the paradox of travelers find existing security measures inadequate while at the same time believing air travel to be sufficiently secure as the security paradox.

In this paper, we seek to offer a possible explanation to this paradox. Through a substantive theory of information and communication technology (ICT) use at the airport security checkpoint, we explore this explanation against the background of the emergence of the safety state (Raab 2005). Through the substantive theory, we argue that manufacturing accomplices is a core process of the security checkpoint. By this, we mean that travelers are coerced into taking actions that are indispensable for the checkpoint to function properly. With limited latitude of actions, travelers are forced into participating in a system many of them find ethically and morally objectionable. Yet, active participation makes it difficult for them to object to the moral and ethical issues of their actions without damning themselves. Our explanation of the security paradox is, therefore, that while travelers remain critical of airport security, they avoid damning themselves by criticizing the system in terms of its own logic. They have been made accomplices.

The substantive theory and the following discussion is the main contribution of this paper. We believe this should be of use to three audiences. Our explicit goal with studying the social implications of ICT use in airport security is to engage in research and debate on an issue of political and moral value. Avgerou (2005) argues that more research on such issues is required to challenge the predominant managerial agenda within IS research. Our substantive theory is a contribution toward furthering such a non-managerial agenda. The key audience for this paper is, therefore, other IS researchers who are involved with design research, action research, or policy analysis to actively bring about social change. Second, we hope our theory may contribute to reflection among IS researchers in general on the more problematic effects of ICT diffusion. Finally, this research is also a contribution to the broader interdisciplinary debate on social implications of airport security. While research exists on issues such as surveillance and social sorting (Lyon 2006), the ICT perspective of this paper offers an original contribution to this debate.

The remainder of the paper is organized as follows. First, we present key elements of our perspective on airport security, ICTs, and the safety state. We then present the research setting and methods, before progressing with the analysis. We discuss the analysis and conclude by offering a possible explanation to the security paradox.

\section{Airport Security, ICT Use, and the Safety State}

Few sites are more iconographic of the opportunities and vulnerabilities of contemporary globalization than international airports (Salter 2008a). As a central icon of modern culture, the airport has continuously changed in reflection of contemporary society (Gordon 2004). Reflecting the adventurous spirit of the early 1900s, the airport was originally a point of departure for journeys into the unknown. During its golden years in the late 1950s and early 1960s, the airport was a glamorous and futuristic meeting point for jetsetters and globetrotters. Following the increasingly 
turbulent geopolitical climate of the 1960s, the 1970s exploded in a series of highprofile terror attacks on airports and aircraft. Since then, anti-terror measures have turned airports into an electronically controlled environment, the fortress airport, "a place of jaded realism, apathy, and paranoia" (Gordon 2004, p. 229).

It is this electronically controlled environment that interests us. We regard airport security as an ensemble (Orlikowski and Iacono 2001) of technologies, organizations, laws, and regulations, as well as airport personnel and travelers. ICTs, understood as computer- and software-based technologies dedicated to collecting and processing information (Lyytinen and King 2006), are embedded as integral and ubiquitous elements of this ensemble. The ICTs in the airport ensemble range from conventional information systems such as passenger booking systems, through computer-assisted passenger screening systems (Bennett 2008), to computer-based security technologies such as X-ray machines, electromagnetic archways, backscatter x-ray machines, and explosives detection systems (Salter 2008b).

Few places apart from airports are equally explicit about creating "a public expectation for absolute security" (Salter 2008b, p. 1). While public perceptions are an important part of the security paradox, airport security also needs to be considered against the broader societal background of the emergence of the safety state (Raab 2005). The safety state elevates safety to the preferable condition for situations, institutions, and organizations. Social inequality is no longer the main concern in the safety state. Instead, the safety state is concerned with increasing safety through managing risks. The rise of the safety state is, therefore, closely related to the notion of the risk society. Beck (1992) uses this term to argue that the unpredictability of events and the increased number of risks we face are the most prevalent characteristic of contemporary society. Managing risks to increase safety is, therefore, the positive goal of policy in the risk society. However, Giddens (1999) points out that the idea of risk society does not mean that the world has become more hazardous, but rather that a society increasingly occupied with safety generates the notion of risk.

Risk is a problematic term. Different academic disciplines and even authors within the same discipline use the term differently. Within the technical literature, a much used definition of risk is "the potential for realization of unwanted, negative consequences of an event" (Rowe 1977, p. 24). Douglas and Wildavsky (1983), however, observe that there is a difference between knowable and unknowable dangers. Concerned with the impact and probability of risk, the technical literature is concerned with knowable dangers. Unknowable dangers, on the other hand, reside in the realm of speculation. It is these unknowable risks that arise within the risk society and with which the safety state seeks to come to grips. Yet, for these kinds of risks, quantitative assessment is inherently problematic. Zedner (2006) proposes to differentiate between risk assessment and risk management to address this challenge. Risk assessment is the technical activity of calculating the probability and cost of unwanted events. This is related to knowable risks. Risk management, on the other hand, deals with the ethical, political, and social implications of decision making.

As we acknowledge that unknowable risks often can't be anticipated, Beck (1992) argues that we become more geared to detecting and managing potential risk. Related to safety, such an emphasis on potentiality is an important contributor to what Hornqvist (2004) calls the security mentality. The security mentality replaces law with security as the principle from which physical force and other coercive measures 
proceed. Whereas law emphasizes what a person has done, the security mentality shifts focus to what people may do. It is a shift toward trying to determine if a person constitutes a risk. In the security mentality, the presence of positive indicators is replaced with the absence of negative indicators. The absence of negative indicators, however, is faced with the problem of sufficiency: "one can never know whether one is doing enough to prevent a hazard from occurring" (Douglas and Wildavsky 1983, p. 4).

Airport security is based on screening passengers prior to departure. Computerassisted passenger profiling systems are used to screen travelers against a database of suspected terrorists after booking their tickets (Bennett 2008). At the airport, security technologies such as x-ray machines, electromagnetic archways, backscatter x-ray machines, and explosives detection systems are used to screen passengers moving from the check-in to the boarding area (Salter 2008b). These are all computer-based technologies. Current airport security screening is, therefore, a form of ICT-enabled risk management (Scott 2000). Screening as a risk management strategy is a good illustration of the shift from law to security. Passenger screening procedures treat all travelers as possible security threats. It is not until proven otherwise, through the absence of negative indicators, that travelers are considered no threat to security.

\section{Research Setting and Methods}

We substantiate our explanation of the security paradox through a substantive theory of ICT use at the security checkpoint. This substantive theory has been constructed as part of a study of ICT use in airport security. In this section, we first introduce the research setting. We then present the research methods employed in this study.

\subsection{The Airport}

We have studied ICT use at the security checkpoint at one of Norway's largest airports. For confidentiality reasons, we simply call it the Airport. The Airport has daily international arrivals and departures. It is also a national hub. This means that many travelers catch connecting flights either abroad or to other parts of the country at the Airport. Approximately 3 million travelers pass through the Airport every year. In comparison, approximately 15 million travelers pass through Norway's national airport every year, while 67 million travelers pass through the world's busiest airport, London Heathrow, every year.

Like most international airports, the Airport is an umbrella organization. Numerous stakeholders are responsible for different functions. These stakeholders include airlines, baggage handling companies, catering companies, security companies, police, and customs. The Airport Operator owns the Airport, and is responsible for implementing airport security in compliance with national and international regulations. The daily operation of airport security, however, is subcontracted to the Security Company. Civil aviation authorities use the term security to refer to safeguarding airports and aircraft "from acts of unlawful interference" (Karimbocus 2008).

While airport security encompasses perimeter watch, luggage checking, and general access control to restricted areas of the Airport, we have focused our study on 
the security checkpoint between the check-in and boarding area, as this is the part of airport security with which travelers interact directly. Figure 1 offers a schematic overview of the security check.

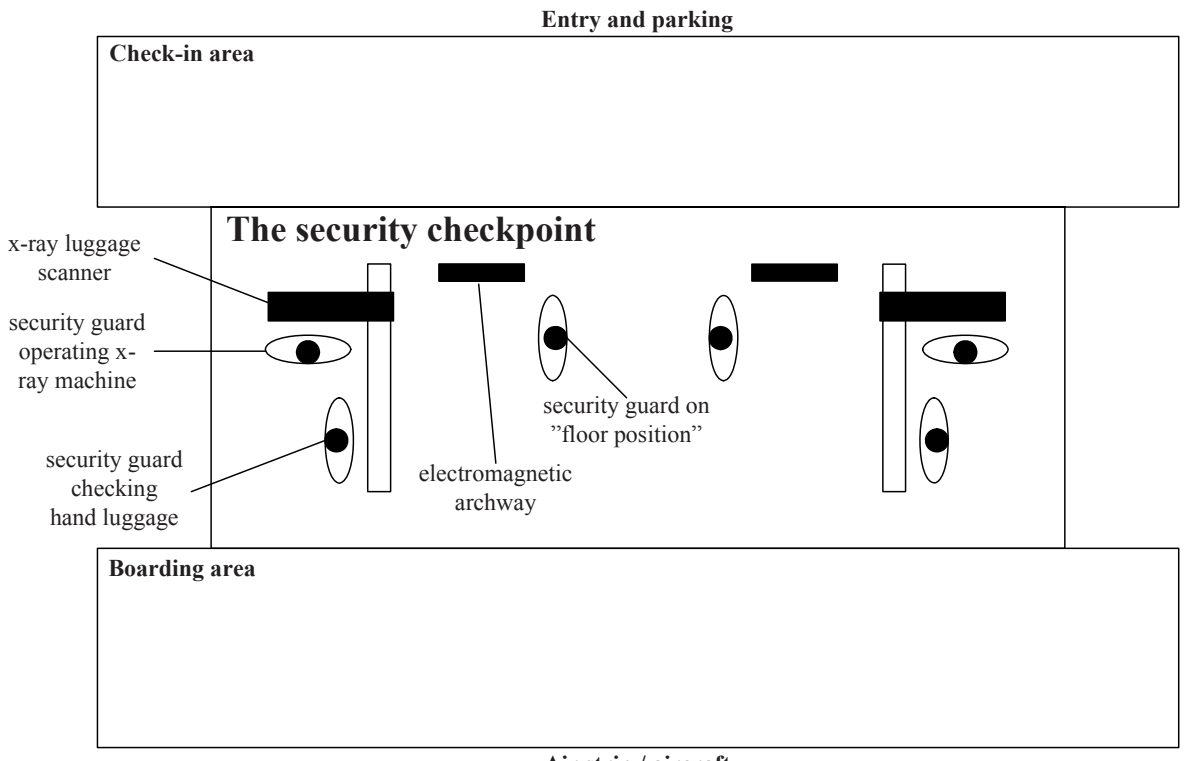

Air strip / aircraft

Fig. 1. Overview of Security Checkpoint

The security checkpoint is organized in three positions. The security guard on floor position is responsible for doing secondary checks when the electromagnetic archway indicates metal on travelers passing through. This secondary check is a full body search. One security guard mans the x-ray luggage scanner. The security guard in the third position does secondary checks on luggage when the x-ray machine indicates suspicious objects.

\subsection{Research Methods}

This research draws on grounded theory as formulated by Charmaz (2006) to construct a descriptive and explanatory theory of ICT use at the security checkpoint. Whitley and Hosein (2007) argue that we as IS researchers are well positioned for contributing to the public debate with concepts that offer insight into the relationship between ICTs and their wider societal context. As the stated purpose of this research is to engage in research and debate on a social issue, we find grounded theory's emphasis on conceptualization particularly well suited for our purpose.

Grounded theory is commonly used within IS research as a set of analytic techniques for coding qualitative data (Urquhart 2002). Our main concern with using grounded theory, however, has been to systematically conceptualize ICT use at the security checkpoint through a constant comparative process (Glaser 2002). We have, 
therefore, used different coding techniques, extensive memo writing, and the progressive integration of codes into concepts and concepts into categories in support of the constant comparative process.

For comparative purposes, we decided to interview both travelers and security guards. Table 1 summarizes the interviews. We had free access to interview travelers at the Airport. The Security Company, however, had two requirements for allowing us to interview security guards. First, they offered us 30 minutes of interview with 10 security guards over a period of 3 days. Second, the Security Company insisted that we use an interview guide they approved prior to the interviews.

Table 1. Number and Types of Interviews Performed at the Airport

\begin{tabular}{|l|c|c|c|c|}
\hline \multicolumn{1}{|c|}{ Interview Sessions } & $\begin{array}{c}\text { Security } \\
\text { Guards }\end{array}$ & Shift Leaders & Travelers & Total \\
\hline October 27, 2008 & - & - & 4 & 4 \\
\hline October 31, 2008 & - & - & 15 & 15 \\
\hline November 17, 2008 & - & - & 10 & 10 \\
\hline November 25, 2008 & 2 & 1 & - & 3 \\
\hline November 26, 2008 & 3 & 1 & - & 4 \\
\hline November 27, 2008 & 2 & 1 & - & 3 \\
\hline Total & 7 & 3 & 29 & 39 \\
\hline
\end{tabular}

Collecting data through theoretical sampling supports the constant comparative method. In grounded theory, data collection and analysis is iterative. The Security Company agreed that we used the interview guide as the starting point for an openended conversation with the security guards. Still, their two requirements by and large prevented us from iteratively collecting and analyzing data from our interviews with security guards. These requirements have limited our ability to fully explore variations in the processes occurring at the security checkpoint.

We sought to compensate for these limitations during analysis. In addition to lineby-line coding of individual interviews and extensive memo writing, we constructed analytical categories through a process of (1) comparing codes within individual interviews, (2) comparing codes between interviews with security guards, (3) comparing codes between interviews with travelers, and (4) comparing codes between interviews with travelers and security guards. We then elaborated on these categories by making comparisons between categories under different conditions such as (1) time of day, (2) travelers' age, gender, and flying frequency, as well as (3) security guards' job experience. Finally, we sought to integrate the categories by putting relevant categories into a coherent argument.

The analysis below refers to quotes from interviews with security guards on the form "G\#<number $>$ : $<$ paragraph" and with travelers on the form "T\#<number $>:<$ paragraph $>$." " $<$ number $>$ " indicates the unique identifier assigned the interview, while " $<$ paragraph $>$ " indicates the paragraph in the transcribed interview where the quote is found. 


\section{Analysis}

The security checkpoint is caught in an inherent contradiction between two conflicting functions at the Airport. The overall function of the Airport is to facilitate rapid movement of people between places, both within the Airport as well as to other airports. Yet, the "security checkpoint is an obstacle" (G\#10:47) to this. Screening travelers and hand luggage disrupts such rapid movement within the Airport and consequently also between airports. This section argues that making the security checkpoint function properly in relation to the overall function of the Airport is a collective achievement of travelers and security guards alike in interweaving competing temporal rhythms. In this analysis, we seek to show how travelers as well as security guards play an active role in minimizing disruptions to the rapid movement of travelers between the check-in and boarding areas.

We elaborate on this argument by looking at two major processes of the security checkpoint. Reconciling the conflicting functions requires the active participation of travelers as well as security guards. The first process, interweaving temporal rhythms, elaborates this. At the security checkpoint, travelers have to abide by a strict program of action to minimize disruptions to the flow of travelers. Failure to enact this program of action is met by a series of sanctions. The second major process, disciplining disobedience, elaborates this.

\subsection{Interweaving Temporal Rhythms}

The Airport is bustling with activity from the time it opens in the morning until it closes for the night. It is constantly filled with people on the move between places. It is never quiet, always buzzing with the background sounds of a multitude of activities. Often unrecognized by the ordinary traveler, the intensity of these background sounds ebbs and flows throughout the day, following deeper patterns as the Airport resonates with the throbbing of interweaving temporal rhythms. These rhythms are temporal structures (Orlikowski and Yates 2002) that the Airport's many denizens enact as they go about their activities.

The security checkpoint's temporal rhythm is also intertwined with several of the Airport's other rhythms. The production of security, therefore, has to be conceptualized in the context of the temporal rhythms that run through and intertwine at the security checkpoint. Producing security is not merely about securing the Airport. It is equally concerned with intertwining the temporal rhythms that run through and intersect at the checkpoint. In particular, it is about the activity of interweaving competing rhythms to avoid disrupting the flow of people between the check-in and boarding areas.

\subsubsection{Temporal Rhythms at the Security Checkpoint}

The flight schedule is the heartbeat of the Airport. Practically all of the Airport's activities resonate with this temporal rhythm. In the morning, Airport staff open the Airport in preparation for the day's first departures and arrivals. Late at night, as the last arrivals drain out the building, Airport staff close the Airport. For the security guards at the checkpoint, the flight schedule is experienced as a sequence of peak and off-peak periods. 
The day starts somewhat abruptly [with many flights], when you have a lot of queues and stress... .Then there are off-peak periods of calm where we eat and so on, and then we have a couple more peaks throughout the day. (G\#2:13)

Travelers enact this temporal rhythm in moving through the security checkpoint in time for their flights. They follow the rhythm of traveling: arriving at the airport, checking in, passing through the security checkpoint, and boarding. In order for travelers to reach their flights, this sequence of activities needs to follow the flight schedule. Yet, at the security checkpoint, these two rhythms interweave with the checkpoint's own temporal rhythm. The sequence of activities in this rhythm is more erratic than that of the flight schedule and of traveling. Certain activities such as sending objects through the x-ray, passing through the electromagnetic archway, and reclaiming hand luggage are stable. This is followed by the security guards at the checkpoint, who inspect the luggage in the x-ray machine and observe the electromagnetic archway. The sequence is repeated with each traveler passing through the security checkpoint. This is the cycle of the checkpoint's rhythm.

The secondary check, however, is a more sporadic part of the checkpoint's rhythm. The guard on floor position performs a secondary check on travelers when the archway sounds the alarm. The guard manning the x-ray machine indicates to his colleague in the luggage check when there is need for a secondary check of the hand luggage.

The warning bell starts chiming at once when you see something you don't recognize, or when there is so much clutter in the luggage that you cannot see properly through. We simply have to open and take a look inside, it is as simple as that. That is our drill. (G\#6:27)

While the regular sequence in the security check is of limited impact on the overall flow of people through the checkpoint, secondary checks have more impact. We will, therefore, elaborate on the temporal interactions between rhythms.

\subsubsection{Temporal Interactions}

The temporal rhythms enacted by travelers and security guards at the checkpoint interact as their sequences and cycles interweave with each other. Temporal interaction affects the rhythms' tempo. Every temporal rhythm has its own tempo. Whereas sequences are often fixed, tempo need not be fixed. While travelers have to check in and pass through the security checkpoint before they can board the aircraft, they can speed up the tempo of the rhythm by running from the security checkpoint to the gate.

Security guards talk of temporal interactions in terms of their experience of the checkpoint as busy or intense. The checkpoint is busy "in the morning when there are a lot of businesspeople, which we see on the throughput as things move along quickly with businesspeople [because] they travel three or four times a week" (G\#3:45). While there are a lot of travelers passing through the busy security checkpoint, the temporal rhythms are in harmony. When temporal rhythms are in harmony, they have limited impact on each other's tempo.

In contrast, when the checkpoint is intense, there is a lot of "queuing and stress"

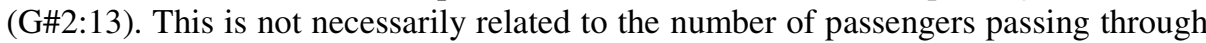


the checkpoint, but rather that the rhythms compete. Rhythms are competing when one rhythm interrupts the tempo of another rhythm. This is the kind of temporal interaction that causes the inherent tension between securing the flow of people through the checkpoint and the secondary check. This leads to temporal disruptions.

\subsubsection{Interweaving Competing Rhythms}

The security checkpoint fills up with travelers as temporal rhythms compete for the travelers' and security guards' attention. First, throughput starts dwindling as travelers have to wait before walking through the electromagnetic archway; then, it ceases completely as the security checkpoint fills up, preventing waiting travelers from passing through the archway. In response, the queue grows, tempers flare, and, as a security guard put it, "It is obvious, you know, that nobody remains unaffected when the queue stretches all the way to the gas station [down the road from the Airport]" (G\#6:15).

Travelers and security guards alike have to simultaneously enact multiple temporal rhythms at the security checkpoint. The ICT-based technologies at the checkpoint, however, have few such concerns. They relentlessly exact their own timetable. When the archway indicates metal objects on a traveler, it cares little about the length of the queue or travelers' departures. It sounds the alarm regardless, and a security guard has to perform a secondary check. Similarly, when the x-ray indicates prohibited objects in the hand luggage, a security guard has to perform a secondary check of the hand luggage. The secondary check follows its own tempo, disrupting the tempo of people flowing through the checkpoint.

I don't feel I'm affected by stress. I take things in the correct tempo. A secondary check is to take approximately two minutes, regardless [of the qиеие]. (G\#5:91).

Similarly, technologies disrupt the cycle of travelers. Once the archway has detected metal, the security guards "do not give up until [the archway] stops beeping" (G\#4:18). It therefore befalls travelers and security guards to interweave competing rhythms to reduce temporal disruptions at the checkpoint.

Travelers are active participants in interweaving the competing rhythms by abiding by a program of action aimed at not triggering a secondary check by not carrying prohibited items in the hand luggage or on their person. It is the process of enrolling and keeping travelers in this program of action to which we will now turn.

\subsection{Disciplining Disobedience}

Reducing temporal disruptions to ensure rapid movement of people between the check-in and boarding areas is indispensable for the proper functioning of the security checkpoint as part of the Airport as a whole. Interweaving competing rhythms to reduce temporal disruptions is the key to facilitating such rapid movement of people. Without travelers' active participation, temporal disruptions threaten to reduce the movement of travelers between the two areas.

Through its material setup of information signs, queuing lines, tables, and ICTs such as hand luggage x-ray scanners and electromagnetic archways, as well as routines for sorting hand luggage in separate trays and standardized plastic bags, the 
security checkpoint inscribes a program of action (Latour 1999). This program of action is aimed at reducing the temporal disruptions to the flow of people through the checkpoint. Failure to comply with the inscribed program of action is met with an array of sanctions.

The security checkpoint is a total system in that it is enforced as the obligatory passing point (Latour 1999) for anyone wanting to travel by plane. The traveler has to pass through the security check to board the aircraft. As one security guard put it, "We just have to tell them [travelers] that we can't let them pass if they won't let us control them, and then they won't catch their plane for sure that usually does the trick” (G\#4:42). Travelers have no choice. Not only do they have to pass the security check to board the aircraft, they have to behave in accordance to the program of action to avoid sanctions.

\subsubsection{Imposing Sanctions}

Travelers and hand luggage are subjected to secondary checks when they are found to carry prohibited objects. Secondary checks cause temporal disruptions as they reduce the number of passengers who can pass through the checkpoint. Secondary checks are, from a security point of view, required to prove that travelers pose no threat to security. This follows from the logic of the security mind set, as risk management at the security checkpoint seeks the absence of negative indicators.

Travelers, however, often regard the activities surrounding the secondary check as sanctions aimed at disciplining disobedience to reduce temporal disruptions. From the point of view of the security guards, the travelers are accountable for the temporal disruption of the secondary checks: "It is their own fault, because they have forgotten to place liquids in the [required] bags, for instance, when they pass through [the checkpoint]" (G\#4:42). They may even use the secondary checks as a way of imposing sanctions on travelers who cause temporal disruptions: "We have to take quite a lot of crap at the checkpoint, so one also has to hit back. So a slight [secondary] check, there are not many [travelers] who appreciate that" (G\#5:39).

From the point of view of travelers, the activities surrounding the secondary check have both means and effects as sanctioning mechanisms. The means are threefold: (1) detention, (2) intrusion of personal space, and (3) confiscation of property. Being pulled over for a secondary check is a form of detention. Many travelers find this reduces their position from that of an independent adult to an inferior person. One traveler explained it this way:

Yes, and then you are incredibly stressed [emphasizes the last two words] because you are standing there and the plane is about to leave and they [the security guards] are detaining you and, like [paraphrasing the security guards] "This is not up for discussion. You are not leaving until we have cleared this situation. The plane will just have to leave without you." (T\#20:10)

Many find body searches and inspections of their hand luggage an intrusion of their personal space: "No one wants to have someone feel them up" (T\#2:7). Security guards will confiscate any prohibited items travelers try to bring through the security check. By deprivation of personal autonomy, we mean that travelers are no longer free to control their own behavior. By inscribing rigid programs of behavior, loss of 
personal autonomy is a central characteristic of the security check. Where the security check seeks to collectively standardize the behavior of travelers, the sanctions for failing to comply with the inscribed program singles out individual travelers for sanctions. For many, being singled out like this amplifies the experience of losing personal autonomy.

Being deprived of personal autonomy is one of the three effects of the sanctions. The other two are public humiliation, and collective punishment.

When a traveler fails to act according to the inscribed program of behavior, sanctions are invoke that involve public punishment. When the metal detector gate beeps, the attention of other travelers is turned toward the non-complying passenger. Body searches, scanning with handheld metal detectors, and luggage searches are performed on the spot, in full display of the other travelers:

They [the security guards] say it is an inconvenience for me to open my suitcase. RUBBISH!!! I find having to put my things on display for everyone to gawk at disagreeable. (T\#14:39)

The effect of such public humiliation, both to the traveler subjected to it, but also to those witnessing it, is to discipline future actions to avoid further sanctions.

Finally, sanctions are collective. When a security guard orders a passenger to take off their shoes or remove a belt before passing through the security gate, those queuing behind him or her have to wait while the traveler does so. While the sanctions themselves are directed at individual travelers, they cause temporal disruptions at the security checkpoint, leading to a longer waiting time for everyone. It is the collective nature of the direct sanctions that lead to the disciplining of the self.

\subsubsection{The Discipline of the Self}

The generative function of the punishments leveled by the security guards' sanctions is that they instill a discipline of the self in travelers. There are two dimensions to this process: (1) regulating personal behavior and (2) personal sanctions.

There is a marked difference in the way experienced and less experienced travelers approach the security checkpoint. While less experienced travelers are unaware of the sanctions at the checkpoint, they tend to show great emotions when the sanctions are imposed upon them. Experienced travelers, on the other hand, have adopted a disciplined approach to the security checkpoint. For them, interweaving temporal rhythms starts while preparing to travel. These travelers embody the security checkpoint's program of action in the way they regulate their personal behavior when traveling.

This discipline of the self is motivated by the intent "to avoid any difficulties at the security checkpoint" (T\#7:16). These are deliberate actions to avoid the sanctions imposed by security guards. At the Airport, prior to entering the security check, individuals also discipline their actions. These are often minor details. One traveler, for instance, said he always makes sure he empties his trouser pockets of all loose change. The loose change is put in his jacket instead. When asked whether loose change will trigger the metal detector accompanied by routines at the airport to avoid secondary check, he responds, "Yes, I think it does [posed halfway between a question and a statement]. Hell if I know. But to make sure ”(T\#8:29). 
Other travelers explain how they start preparing for the metal detector by removing belts, taking off shoes, removing wristwatches, and so on while queuing. All of these small gestures are to avoid problems in the security check.

While many travelers speak of the discipline of the self in terms of "avoiding difficulties at the security checkpoint," these troubles are not only related to the sanctions imposed by the security guards. Travelers also impose personal sanctions on themselves. Many express indignation when fellow passengers trigger a secondary check. When they themselves trigger a secondary check, they project this indignation onto themselves, saying they can literally feel the other travelers glaring at them when they are checked.

\section{Manufacturing Accomplices}

The analysis above pursues the argument that, for the security checkpoint to function properly in relation to the overall function of the Airport, travelers have to actively participate in intertweaving competing temporal rhythms at the security checkpoint. To this end, a set of sanctions enrolls and retains travelers in a particular program of action aimed at reducing temporal disruptions.

Many travelers find the security checkpoint morally and ethically objectionable. They find it demeaning to be "criminalized in a way" (T\#6:10). Through a shift from the presence of positive indicators to the absence of negative indicators (Hornqvist 2004), they are assumed guilty before proven otherwise. Travelers also find the checkpoint, and in particular the secondary checks, intrusive. As all travelers participating in our study believe there is little danger of terror attacks on civil aviation, they think it is pointless to be subjected to such demeaning and intrusive practices.

We were, therefore, not surprised to learn that practically all travelers were critical of the security checkpoint. We were, however, surprised by the nature of the travelers' critique. Practically all travelers, even those who expressed moral and ethical misgivings, criticized the checkpoint in terms of security holes and inconsistencies. We did expect security guards to be concerned with inconsistencies and security holes. It is, after all, their job to secure the Airport. But why do travelers reflect along the same lines?

Several researchers elaborate on how the media, politicians, and corporations prey upon people's basal fearfulness to further their own ends (Stearns 2006). This culture of fear thesis sees contemporary society as regressing into a state of irrational fear. Current escalation of airport security could be seen as an expression of such a regression. While the travelers we have interviewed are indeed preoccupied with the shortcomings of existing security measures at the Airport, none of them express any fears of terror attacks on civil aviation. Indeed, most find the terror threat highly exaggerated.

The culture of fear thesis draws upon a long tradition of thinking that considers civilization a thin, fragile veneer on top of primitive human instincts like fear and aggression. Within this tradition, mankind is not only in constant danger of regressing into a primitive state; it does so on a regular basis. The Holocaust is an oft-used example, where Nazi Germany's regression into barbarism gives rise to mass-slaughter. 
Bauman (2000), however, argues that the Holocaust is better understood in terms of social regulation through a well-functioning bureaucracy. Similarly, risk management is a form of regulation based on identifying impurities to be regulated and managed. Rather than seeing airport security as an expression of a society gripped in fear, airport security is better understood in terms of ever-expanding regulation and bureaucratization.

Before something can be regulated, however, it needs to be known. ICTs are pivotal for those processes through which objects are rendered amenable to intervention and regulation by being formulated in a particular way (Foucault 1991). Civil aviation authorities consider ICTs critical in securing the safety state at airports. However, the crude screening mechanisms these ICTs implement shape the material arrangements and practices at the security checkpoint.

The ICTs seek to render individual travelers and pieces of hand luggage into knowable objects through screening. The problem in terms of the overall functionality of the Airport, however, is that they implement rather crude screening mechanisms. The electromagnetic archway, for instance, indicates the presence of metal objects on travelers, but is unable to differentiate between a knife and a belt buckle. The effect is numerous false alarms unless travelers remove harmless metal objects before passing through the archway. The activities in interweaving competing temporal rhythms and disciplining disobedience are, therefore, aimed at supporting the ICTs by reducing the number of false alarms.

What we find, then, is that travelers are caught in a double-bind situation: while they find it pointless to be subjected to demeaning and intrusive practices, they also find it in their best interest to actively participate in reducing temporal disruptions to avoid delays and "stay out of trouble." Travelers are not merely made compliant through disciplining mechanisms; they find themselves actively engaged in regulating their personal behavior to minimize temporal disruptions. Moreover, while many travelers find the security checkpoint ethically and morally objectionable, they also find themselves taking an active part in disciplining disobedience through openly expressing discontent when other travelers trigger the secondary check. It may, therefore, seem that travelers assume the systemic viewpoint, and find themselves an integral part of the system many of them find morally and ethically objectionable. Through their own actions, however, they incriminate themselves. They are made accomplices, rendering themselves incapable of objecting without also damning their own actions.

\section{Conclusions}

This leads us back to a possible explanation of the security paradox: To avoid damning themselves, travelers assume the systemic viewpoint when encouraged to reflect critically upon the security checkpoint. In so doing, they become preoccupied with security holes and inconsistencies. As such, while the travelers are not particularly worried about the possibility of a terror attack, through their preoccupation with detecting and managing potential risks (Beck 1992), they find existing security measures inadequate in relation to the ideal of absolute absence of danger (Salter 2008a). 
Yet, detecting and managing potential risks with the goal of absolute absence of danger is a never-ending process. While new risks may be discovered, the problem of sufficiency will always loom in the background (Douglas and Wildavsky 1983). One can simply never know whether one is doing enough to prevent hazards from occurring. As such, for as long as absolute absence of danger is the espoused goal, travelers will find airport security inadequate.

We observe similar dynamics at play with legislators and regulating bodies. There is a continued emphasis on introducing new ICTs to secure the safety state at airports. In the process of striving toward the ideal condition of the safety state, however, we stand the chance of losing track of the social costs of securing safety. Our concern is, therefore, that continued emphasis on screening will lead to a continued technological escalation with subsequent expenses and oppressive measures to travelers.

\section{Acknowledgments}

The authors thank the Security Company, its security guards, and travelers at the Airport who have given generously of their time to advance this study. We also thank Charles Raab, colleagues in the Researcher Factory, and three anonymous reviewers for invaluable comments. This work was financed partially through Eric Monteiro and partially through the Research Council of Norway's project 183235.

\section{References}

Avgerou, C.: Doing Critical Research in Information Systems: Some Further Thoughts. Information Systems Journal 15(2), 103-109 (2005)

Avinor, Avinor Annual Report, Avinor, Gardermoen, Norway (2007)

Bauman, Z:: Modernity and the Holocaust. Polity Press, Cambridge (2000)

Beck, U.: Risk Society: Towards a New Modernity. SAGE Publications, London (1992)

Bennett, C.J.: Unsafe at Any Altitude. In: Salter, M. (ed.) Politics at the Airport, pp. 51-76. SAGE Publications, Thousand Oaks (2008)

Charmaz, K.: Constructing Grounded Theory: A Practical Guide Through Qualitative Analysis. SAGE Publications, Thousand Oaks (2006)

Douglas, M., Wildavsky, A.: Risk and Culture: An Essay on the Selection of Technological and Environmental Dangers. University of California Press, Berkeley (1983)

Elphinstone, G.: The Early History of Aviation Security Practice. In: Thomas, A.R. (ed.) Aviation Security Management, pp. 1-8. Praeger Security International, Westport (2008)

Foucault, M.: Governmentality. In: Burchell, G., Gordon, C., Miller, P. (eds.) The Foucault Effect: Studies in Governmentality, pp. 87-104. University of Chicago Press, Chicago (1991)

Giddens, A.: Risk and Responsibility. Modern Law Review 62(1), 1-10 (1999)

Glaser, B.G.: Conceptualization: On Theory and Theorizing Using Grounded Theory. International Journal of Qualitative Methods 1(2), 1-31 (2002)

Gordon, A.: Naked Airport: A Cultural History of the World's Most Revolutionary Structure. Chicago University Press, Chicago (2004)

Hornqvist, M.: The Birth of Public Order Policy. Race Class 46(1), 30-52 (2004)

IATA. The Air Transport Industry Since 11 September 2001, International Air Transport Association, Montreal, Canada (2007) 
Karimbocus, M.: The Human Element in Aviation Security. In: Thomas, A.R. (ed.) Aviation Security Management, pp. 65-76. Praeger Security International, Westport (2008)

Latour, B.: Pandora's Hope. Harvard University Press, Cambridge (1999)

Lyon, D.: Airport Screening, Surveillance, and Social Sorting: Canadian Responses to 9/11 in Context. Canadian Journal of Criminology \& Criminal Justice 48(3), 397-411 (2006)

Lyytinen, K., King, J.L.: Standard Making: A Critical Research Frontier for Information Systems Research. MIS Quarterly (30:special issue), 405-411 (August 2006)

Orlikowski, W.J., Iacono, C.S.: Research Commentary: Desperately Seeking the 'IT' in IT Research-A Call to Theorizing the IT Artifact. Information Systems Research 12(2), 121$134(2001)$

Orlikowski, W.J., Yates, J.: It's About Time: Temporal Structuring of Organizations. Organization Science 13(6), 684-700 (2002)

Raab, C.D.: Governing the Safety State, inaugural lecture, University of Edinburgh (2005)

Rowe, W.D.: An Anatomy of Risk. John Wiley \& Sons, Inc., New York (1977)

Salter, M.: Airport Assemblage. In: Salter, M. (ed.) Politics at the Airport, pp. i-xix. University of Minnesota Press, Minneapolis (2008a)

Salter, M.: The Global Airport: Managing Space, Speed, and Security. In: Salter, M. (ed.) Politics at the Airport, pp. 1-28. University of Minnesota Press, Minneapolis (2008b)

Scott, S.V.: IT-Enabled Credit Risk Modernization: A Revolution Under the Cloak of Normality. Accounting, Management and Information Technologies 10(3), 221-255 (2000)

Stearns, P.N.: Fear and Contemporary History: A Review Essay. Journal of Social History 40(2), 477-484 (2006)

Steria. Positive til biometrisk sikkerhetsteknologi (2007), http://www.steria.no/gloria/id/11003246/subid/0

TØI. Trygt eller truende? Opplevelse av risiko på reisen, Report 913/2007, Norwegian Institute of Transport Economics, Etterstad, Norway (2007)

Urquhart, C.: Regrounding Grounded Theory-Or Reinforcing Old Prejudices? A Brief Reply to Bryant. Journal of Information Technology Theory and Application 4(3), 43-54 (2002)

Whitley, E.A., Hosein, I.R.: Policy Engagement as Rigorous and Relevant Information Systems Research: The Case of the LSE Identity Project. In: Proceedings of the 15th European Conference on Information Systems, St. Galen, Switzerland, June 7-9, pp. 1301-1312 (2007)

Zedner, L.: Neither Safe Nor Sound? The Perils and Possibilities of Risk. Canadian Journal of Criminology \& Criminal Justice 48(3), 423-434 (2006)

\section{About the Authors}

Thomas Østerlie is a postdoctoral fellow at the Department of Computer and Information Science, Norwegian University of Science and Technology, where he also earned his Ph.D. His research focuses on the dynamic relationship between ICTs and their wider context of development and use. In particular, he is concerned with the relationship between ICT-enabled risk management and social change. Thomas can be reached at thomas.osterlie@idi.ntnu.no.

Ole Martin Asak received an M.Sc. in informatics from the Norwegian University of Science and Technology. His research has focused upon how security is produced at airports in the interplay between security guards and ICTs in everyday work. Ole 
Martin has a background as a security guard himself. He is currently working as a system developer at Adactus and can be reached at ole_asak2@hotmail.com.

Ole Georg Pettersen earned an M.Sc. in informatics from the Norwegian University of Science and Technology. Ole Georg is currently working as a software consultant with SiriusIT, and can be reached at olegeorg@gmail.com.

Håvard Tronhus received the M.Sc. in informatics from the Norwegian University of Science and Technology. Together with Ole Georg, he has studied travelers' experience of security and danger in encountering airport security. Håvard can be reached at havard@ tronhus.net. 